\title{
EFFECT OF FISH OIL ON ALVEOLAR BONE OF RATS WITH INDUCED RHEUMATOID ARTHRITIS
}

\author{
Nihal T. Elkazzaz ${ }^{\prime *} M S$, Salwa Y.AbdElSamad ${ }^{2} P h D$, Khadiga Y. Kawana ${ }^{2} P h D$, \\ Azza S. Kora ${ }^{3} P h D$
}

\begin{abstract} of anti-inflammatory drugs needed to control the RA symptoms. and ultrastructurely in the different groups. the blood.

KEYWORDS: Alveolar bone, Fish oil, Induced rheumatoid arthritis, Freund's complete adjuvant

1- Assistant lecturer of Oral Biology - Faculty of Dentistry - Alexandria University

2- Professor of Oral Biology - Faculty of Dentistry - Alexandria University.

3- Assistant Professor of Oral Biology - Faculty of Dentistry - Alexandria University.
\end{abstract}

INTRODUCTION: Although rheumatoid arthritis (RA) is primarily a chronic inflammatory autoimmune disease which affects the synovial joints, it has profound effects on bone remodeling characterized by increase osteoclastic activity, and a negative balance of bone formation and resorption. A strong correlation has been reported between RA and periodontitis with subsequent alveolar bone resorption. As a potent antiinflammatory mediator, fish oil rich in omega-3 polyunsaturated fatty acids ( $\mathrm{n}-3$ PUFA) has demonstrated beneficial actions in various inflammatory conditions including RA and cardiovascular disease. High intakes of n-3 PUFA provide symptomatic relief and reduce the doses

OBJECTIVES: To evaluate the biological effect of fish oil on alveolar bone of rats with induced rheumatoid arthritis.

MATERIALS AND METHODS: Twenty one male albino rats were used in this study. The rats were divided into 3 groups 7 rats each. Group I: control group, Group II: RA induced group and Group III: RA induced group + fish oil. Rheumatoid arthritis induction was done by single subcutaneous injection of Freund's complete adjuvant. Fish oil was orally gavaged daily till the end of the experiment. Laboratory investigations were performed twice, after RA induction and at the end of the experiment. Effect of fish oil on alveolar bone of rats was assessed histologically

RESULTS: Remarkable improvement in the histology and the ultrastructure of the alveolar bone of rats in Group III was observed. Moreover, hematological values revealed significant decrease in the inflammatory condition of rats with induced RA after fish oil treatment.

CONCLUSION: Rheumatoid arthritis is an important risk factor for alveolar bone loss. The treatment of the RA induced rats with fish oil not only prevented the alveolar bone resorption and stimulated new bone formation, but also reduced relatively the level of rheumatoid factor in

\section{INTRODUCTION}

Rheumatoid arthritis (RA) is a chronic, systemic, immunemediated inflammatory disease associated with decreased life expectancy and quality of life. RA is characterized by chronic inflammation and synovial hyperplasia leading to destruction of cartilage and bone (1).

The diagnosis of RA is primarily clinically, where the typical presentation is pain, stiffness, and swelling of multiple joints in a bilateral and symmetric pattern (2). Initial laboratory tests should include a complete blood count, rheumatoid factor (present in about $80 \%$ of cases of RA) and erythrocyte sedimentation rate (ESR, a blood marker of inflammation) (3).

Rheumatoid arthritis synovial fluid has been shown to contain a wide range of molecules including proinflammatory cytokines (Interleukin; IL-1 $\beta$, IL-6, IL-18 and Tumor necrosis factor; TNF- $\alpha$,), chemokines such as (IL-8, interferon gamma-induced protein (IP-10), monocyte chemoattractant protein 1(MCP-1) and matrix metalloprotinases MMPs (MMP-1,-3,-9 and -13). This complex interaction causes a cycle of proinflammatory signals resulting in chronic and persistent inflammation (4).

Rheumatoid arthritis synovial tissues also exhibit an increases ratio of Receptor activator of NK-kappa ligand/ osteoprotegrin (RANKL/OPG) mRNA expression, indicating

the domination of pro-osteoclastogenic conditions within the microenvironment of the RA joint, which contribute to the focal bone erosions and periarticular bone loss (5).

Bone involvement typically observed in RA is represented by generalized osteoporosis and localized bone loss. Extracellular matrix degradation is a hallmark of RA which is responsible for the typical destruction of cartilage, ligaments, tendons and bone. Bone loss associated with RA usually converges toward an alteration of bone remodeling processes characterized by the increase of osteoclast activity, with a negative balance of bone formation and resorption (6).

Rheumatoid arthritis is reproduced in rats either by immunization with type II collagen or by complete Freund adjuvant injections. Adjuvant arthritis induced by administration in rats has been shown to be similar in many aspects of human rheumatoid arthritis and is used as a model for studying the evolution of the pathological process and the effectiveness of the components that present antiinflammatory and antirheumatic activity (7).

Several studies have suggested a relationship between periodontitis and RA; where the latter may have a negative impact on periodontal condition and vice versa. There is a significantly high prevalence of moderate to severe periodontitis in individuals with rheumatoid arthritis (8-10).

Essential fatty acids are critical for the growth and division of all cells and the formation of healthy cell membranes. They are also necessary for the proper development and function of the brain and nervous system (11).

Fish oil is a key provider of health-beneficial omega-3 long chain polyunsaturated fatty acids. It also contains small concentrations of dietary-derived vitamin $\mathrm{E}$ which plays an important role in preventing PUFA oxidation (12).

The beneficial actions of dietary n-3 PUFA supplementation were demonstrated in various 
inflammatory conditions in humans including rheumatoid arthritis, cardiovascular disease, and inflammatory bowel disease and in a wide variety of animal models of inflammatory disease (13-14).

Patients with recent-onset or more established RA achieve better disease control when anti-inflammatory doses of fish oil are co-administered with appropriate intensive combination disease-modifying anti-rheumatic drug (DMARD) therapy (15). Moreover, several investigators have reported that rheumatoid arthritis patients consuming $\mathrm{n}-3$ dietary supplements were able to lower or discontinue their background doses of nonsteroidal anti-inflammatory drugs or disease-modifying anti-rheumatic drugs (16).

The supplement fish oil diet is effective in modulating alveolar bone resorption following $P$. gingivalis infection, and can be a useful adjunct in the treatment of periodontal disease (17). It causes decrease in osteoclast activation in vitro (18). It is believed that bioactive products derived from omega-3 fatty acids, including docosahexaenoic acid (DHA) and eicosapentaenoic acid (EPA), conferred dramatic protection against inflammation-induced tissue and bone loss associated with periodontitis in the experimental models (19).

This work was carried out to evaluate the effect of fish oil on the structure of alveolar bone of rats with induced RA.

\section{MATERIALS AND METHODS}

Twenty one male albino rats weighing about 200-250 grams were used in this study. The guidelines for the care and use of experimental animals were followed according to the Institute of Medical Research, Alexandria University from where the animals were obtained and the work was done. Rats were divided into 3 groups 7 rats each.

Group I: Control group. Rats were injected with vehicle (citrate buffer) to control the influence of any injection stress or buffer-induced effects on the animals. Group II: RA induced group. Rats were subcutaneously injected once by $0.1 \mathrm{ml}$ of Freund's complete adjuvant (FCA) into the posterior paw of rats in group II \& III (20). Group III: RA induced group + fish oil. Fish oil was supplied at $40 \mathrm{mg} / \mathrm{kg}$ orally gavaged daily starting after RA induction (day 10 from FCA injection) till the day of scarification (21).

Clinically, the injected posterior paws of rats in the different groups were observed before and after fish oil treatment.

Laboratory investigations including RBCs and WBCs, erythrocyte sedimentation rate (ESR) and rheumatoid factor were detected in the three groups after 9 days from RA induction and before scarification (22).

Rats were sacrificed after 5 weeks from the start of the fish oil administration. For light microscopic examination, the right halves of the mandibles were fixed in $10 \%$ neutral formalin saline, decalcified, washed, dehydrated, embedded, and then cut and stained with Haematoxylin and Eosin stain (23). Whereas the left halves of the mandibles, were fixed in gluteraldehyde to be prepared for scanning electron microscopy (24).

Statistical analysis of the hematological values was analyzed using IBM SPSS software package version 20.0. ANOVA was used for comparing the three studied groups for normally distributed quantitative variables, while Paired t-test was assessed for comparison between different periods. Significance of the obtained results was judged at the $5 \%$ level (25).

\section{RESULTS}

\section{Clinical observation}

Before fish oil treatment, posterior paws of rats of groups II and III showed obvious inflammatory signs like redness, inflammation and stiffness. While after fish oil treatment, at the end of the experimental period, persistent inflammatory signs were observed in rats of group II, while a remarkable improvement was seen in group III, where there were no signs of redness nor swelling.

\section{Laboratory investigation results}

Table 1 showed the comparison among the three animal groups as regard different parameters including red blood cells (RBCs), white blood cells (WBCs), $1^{\text {st }}$ and $2^{\text {nd }}$ readings of the erythrocyte sedimentation rate (ESR), and rheumatoid factor (RF). Blood samples were obtained after RA induction, while 'Before' and 'After' indicate the timing of taking the samples before and after fish oil treatment. The result indicated that the differences among the three animal groups were statistically significant $(\mathrm{P}$ values $\leq 0.05)$ as regards all different parameters before and after fish oil treatment.

\section{Histological and ultrastructure results \\ Group I: Control group}

The overall histological features of the alveolar bone in this control group showed normal bone structure. The alveolar bone revealed a smooth, regular and uniform surface traversed at different intervals by Volkman's canals that carry the neurovascular supply from the PDL to the alveolar bone. Continuous osteoblast lining either flattened or plump, was seen along most of the bone surface. Deeply stained parallel resting lines indicating continuous bone formation was clearly seen in most of the examined samples. There were highly cellular marrow spaces present between the thick bone trabeculae lined by flat bone-lining cells along their endosteal surface. Uniform thickness of PDL fiber bundles was noticed between the alveolar bone proper and root cementum along the length of the root (Fig. 1).

Concerning the scanning electron microscopic results, the surface topography of the buccal cortical plate of alveolar bone at the mandiblular region showed generalized smooth bone surface with different sizes of nutritive canals showing regular intact borders (Fig. 2).

Group II: Rheumatoid arthritis induced group (RA induced group)

Examination by the light microscope revealed a generalized irregular alveolar bone surface indicating bone resorption. The resorptive lacunae with or without osteoclasts were noticed along the alveolar bone surface from the cervical region downward passing by the middle and apical regions. Deeply stained reversal scalloped lines were seen within bone trabeculae. Disorganization and relative thickening in the PDL fibers could also be observed along the root length (Fig. 3).

Ultrastructurally, Bone topography of this group revealed rough irregular surface showing areas of multiple resorptive pits and craters. Small nutritive canals were also observed on the irregular bone surface (Fig. 4).

Group III: Rheumatoid arthritis induced group and fish oil (RA induced group + fish oil)

The administration of fish oil to the rats with rheumatoid arthritis induction demonstrated a recognizable improvement to some extent in the state and histological 
structure of the alveolar bone. The alveolar bone regained its smooth regular surface with the absence of the resorptive lacunae and osteoclasts as well. The insertion of Sharpey's fibers as thick collagen bundles inside the alveolar bone was clearly evident. There was a relative decrease in the number of osteocytes embedded within bony trabeculae and also an insignificant presence of reversal lines was detected. On the contrary, noticeable resting lines were seen (Fig.5).

Regarding the scanning electron microscopic results, the surface characteristics revealed smooth and homogenous surface with numerous nutritive canals showing well defined regular borders compared to the previous group (Fig $6)$.

Table (1): Comparison between the different animal groups according to different parameters before and after fish oil treatment.

\begin{tabular}{|c|c|c|c|c|c|}
\hline & $\mathrm{N}$ & Control & Rheumatoid & Rheumatoid + fish oil & $\mathrm{p}$ \\
\hline \multicolumn{6}{|l|}{$\mathrm{RBC}$} \\
\hline Before & 7 & $4.91^{\mathrm{a}} \pm 0.22$ & $2.79^{\mathrm{b}} \pm 0.23$ & $2.77^{\mathrm{b}} \pm 0.23$ & $<0.001$ \\
\hline After & 7 & $4.90^{\mathrm{z}} \pm 0.16$ & $4.21^{\sqrt[b]{e}} \pm 0.50$ & $4.80^{\mathrm{a} @} \pm 0.34$ & $0.005^{*}$ \\
\hline \multicolumn{6}{|l|}{ WBC } \\
\hline Before & 7 & $6042.9^{z} \pm 1468.4$ & $9707.14^{\mathrm{b}} \pm 546.53$ & $8742.9^{b} \pm 1429.3$ & $<0.001$ \\
\hline After & 7 & $4671.43^{a} \pm 138.01$ & $7414.3^{\mathrm{ab}} \pm 4383.9$ & $10228.6^{b} \pm 446.2$ & $0.003^{*}$ \\
\hline \multicolumn{6}{|l|}{ ESR $1^{\text {st }}$} \\
\hline Before & 7 & $2.43^{\mathrm{a}} \pm 0.53$ & $5.43^{\mathrm{b}} \pm 1.99$ & $5.29^{b} \pm 2.21$ & $0.007^{*}$ \\
\hline After & 7 & $2.43^{a} \pm 0.53$ & $19.57^{b \sqrt{6}} \pm 1.62$ & $6.86^{c} \pm 0.90$ & $<0.001$ \\
\hline \multicolumn{6}{|l|}{$\operatorname{ESR} 2^{\text {nd }}$} \\
\hline Before & 7 & $4.71^{\mathrm{a}} \pm 0.49$ & $11.57^{\mathrm{b}} \pm 3.36$ & $11.57^{b} \pm 3.46$ & $<0.001$ \\
\hline After & 7 & $4.43^{\mathrm{a}} \pm 0.79$ & $41.57^{\mathrm{b} @} \pm 2.76$ & $11.71^{c} \pm 2.29$ & $<0.001$ \\
\hline \multicolumn{6}{|l|}{$\mathrm{RF}$} \\
\hline Before & 7 & $0.77^{a} \pm 0.36$ & $6.06^{b} \pm 1.37$ & $6.40^{b} \pm 0.76$ & $<0.001$ \\
\hline After & 7 & $0.93^{a} \pm 0.21$ & $13.03^{\mathrm{b} \sqrt{\mathrm{A}}} \pm 1.49$ & $2.30^{\mathrm{c}(9)} \pm 0.68$ & $<0.001$ \\
\hline
\end{tabular}

Normally quantitative data was expressed in meean \pm SD and was compared using ANOVA test Different superscripts in the raw are sialisieally significant

(a): Significant between before and after in each group

$*$ : Statistically significant at $\mathrm{p} \leq 0.05$

$\mathrm{a}, \mathrm{b}$ and $\mathrm{c}$ : different letters denote staissically sigmificant differences.

\section{DISCUSSION}

Bone resorption is a key factor of RA where there is a disturbance in the balance between bone resorption by osteoclasts and bone formation by osteoblasts (6). Adjuvant arthritis induced by administration in rats has been shown to be similar in many aspects of RA and is often used as a model for studying the evolution of the pathological process and the effectiveness of the components that present antiinflammatory and antirheumatic activity (26).

The histological results of the present study showed resorbed irregular alveolar bone surface at the molar region of rats due to RA induction. The alveolar bone surface was characterized with some multinucleated giant cells (osteoclasts) housed in saucer shaped Howship's lacunae that was the result of their own resorptive activity.

This result was in agreement with Aizer et al in 2009, who stated that the chronic synovial inflammation in RA can promote osteoclastogenesis, leading directly to both focal and generalized bone loss and increased risk of fractures (27). The result also was consistent with another study involving alveolar bone made by Park et al, in 2011 who reported the increased osteoclastic activity, decreased bone-forming activity and enhanced adipogenesis promote alveolar bone loss in an induced arthritis model in mice, and suggested that these mechanisms could account for the same outcome in human RA (28).

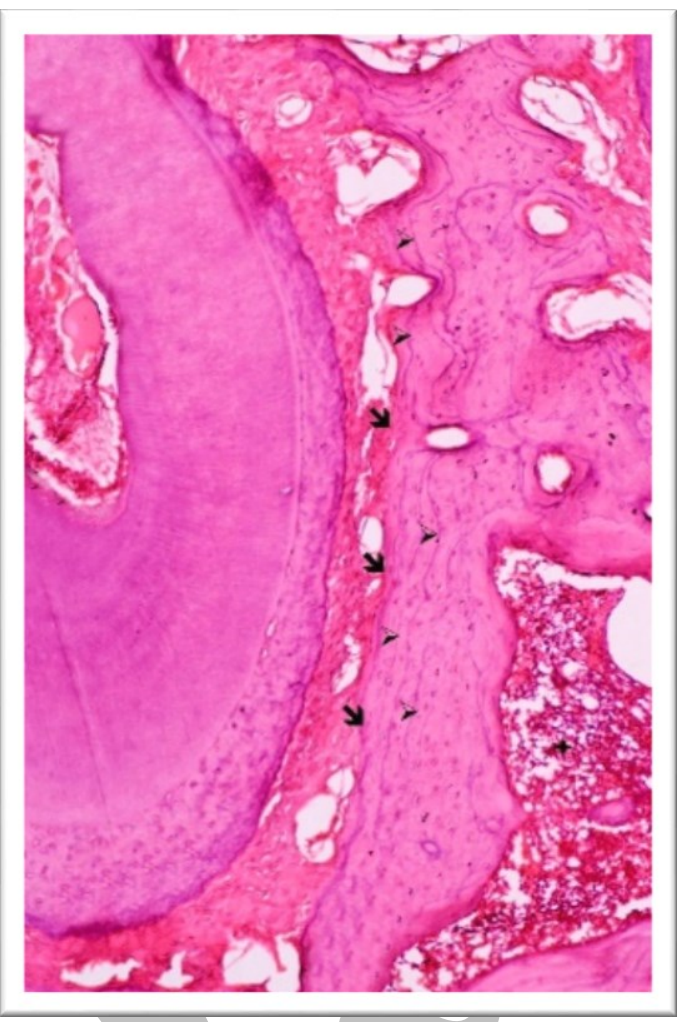

Figure1: Light micrograph [control group] showing smooth regular bone surface along the cervical, middle and apical regions (arrows) with continuous osteoblast lining along bone surface. Deeply stained, well demarcated parallel resting lines were clearly observed (arrow heads). Note the highly cellular bone marrow spaces (asterisk). (X100 H\&E)

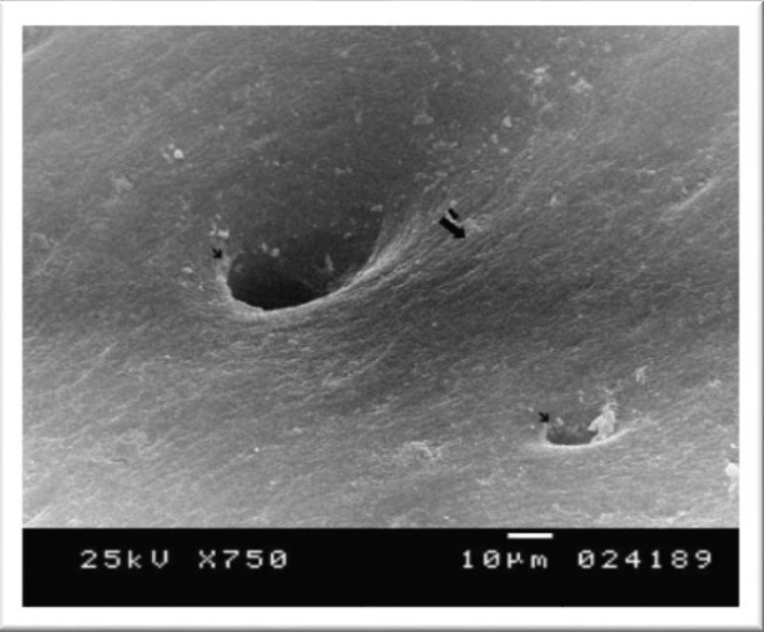

Figure 2: Scanning electron micrograph [control group] of buccal cortical plate showing generalized smooth surface topography with different sizes of nutritive canals (black arrows). $(\times 750)$

As the relationship between inflammation and bone loss has been clearly established in many clinical and experimental models $(29,30)$. Thus, the control of inflammation appears to be one of the most important strategies for prevention of bone loss in RA (31).

In the present study, fish oil was used to evaluate its antiinflammatory effect on the molar region of alveolar bone of RA induced rats. Clinical observations of the injected posterior paws of rats in the different groups in the present study revealed noticeable improvement in the inflammatory 
signs in group III after fish oil treatment which was manifested by the disappearance of redness and swelling. These observations were further confirmed by the laboratory investigation results that showed the therapeutic effect of fish oil on the RA induce rats which were represented by the decrease of the rheumatoid factor and the relative decrease in the erythrocyte sedimentation rate (ESR) and WBC count.

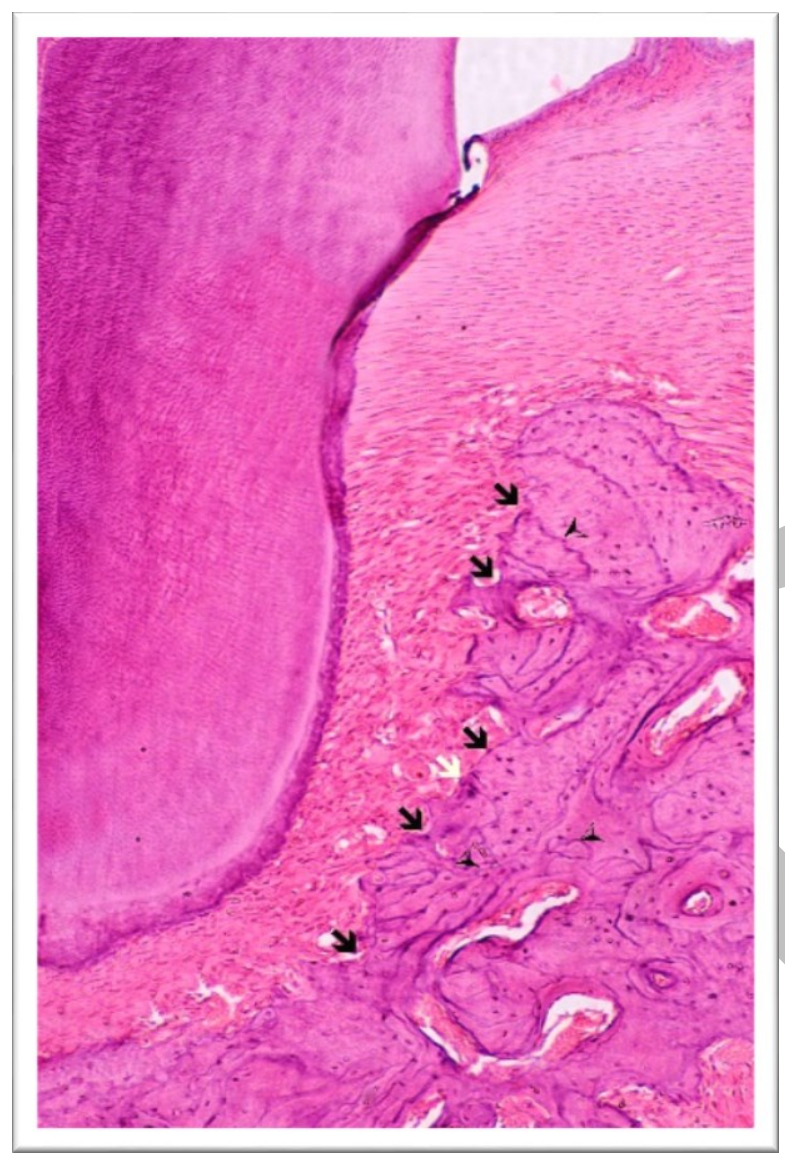

Figure 3: Light micrograph [Rh induced group] showing irregular bone surface (black arrows) with many reversal lines (arrow heads). Note the multinucleated osteoclast (white arrow) (X100 $\mathrm{H} \& \mathrm{E})$

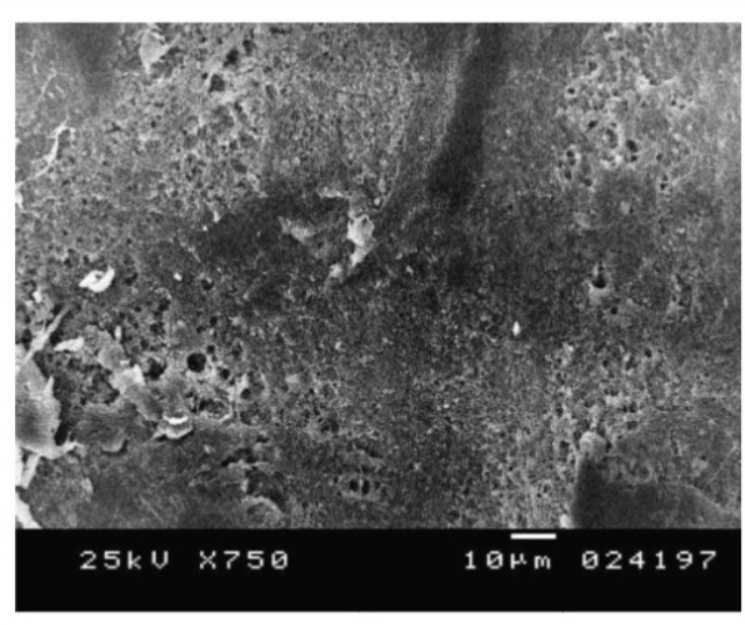

Figure 4: Scanning electron micrograph [RA induced group] of buccal cortical plate showing generalized resorbred irregular bone surface topography with multiple pits and craters. $(\times 750)$

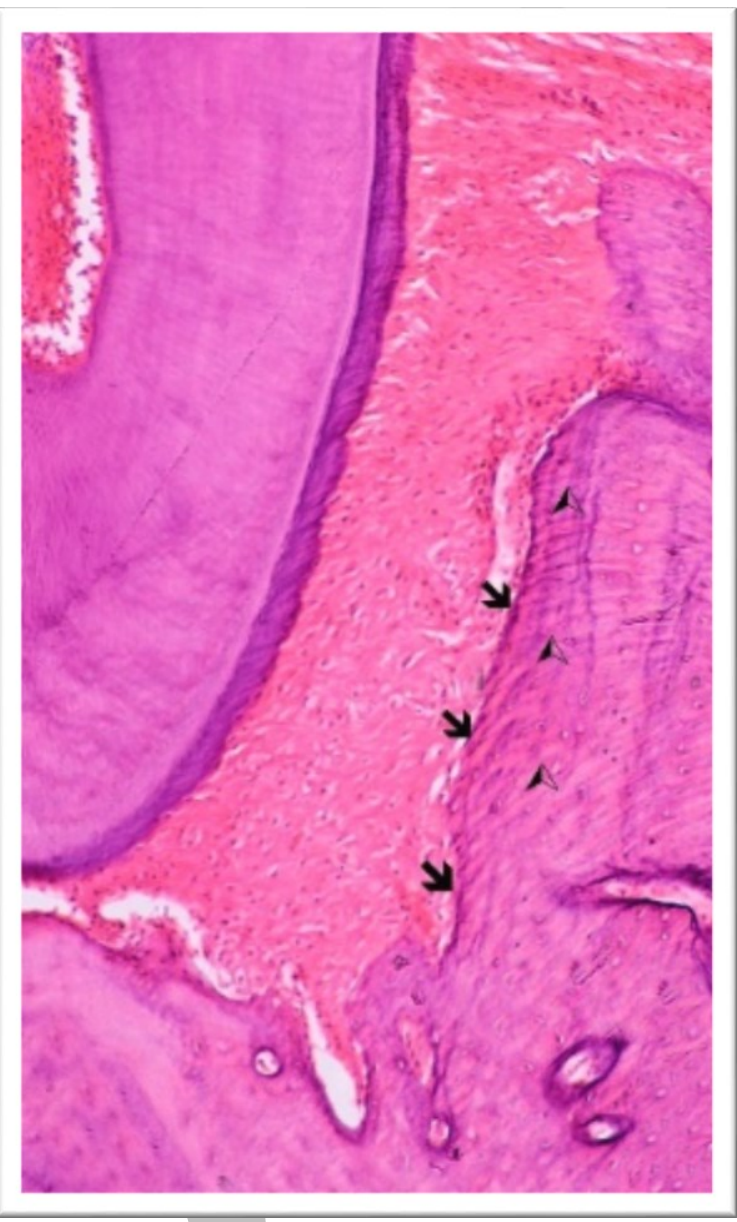

Figure 5: Light micrograph [Rh induced group and fish oil B-III] showing the smooth alveolar bone surface along the alveolar bone with a continuous osteoblast lining (black arrows). Note thick Sharpey's fibers insertion in bone (arrow heads). (X100 H\&E)

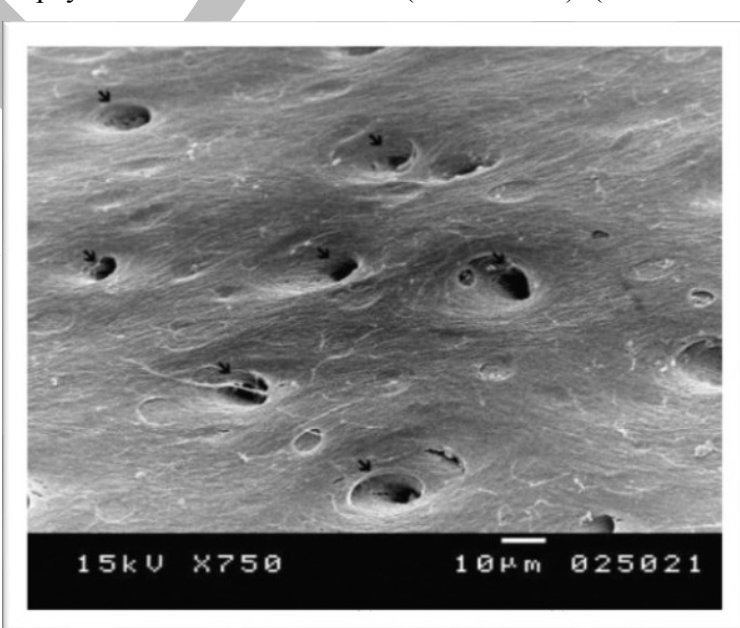

Figure 6: Scanning electron micrograph [RA induced group and fish oil] of buccal cortical plate showing generalized relatively smooth and regular bone surface with numerous nutritive canals (black arrows) $(\times 750)$

The results of the present study agreed with the improved clinical outcomes of Bahadori and colleagues in 2010 that were reported with the use of fish oil or n-3 PUFA in patients with RA (32). These findings were also in agreement with that of Ruggiero et al, in 2009 who reported more convincing data that supported the efficacy of omega3 PUFA in reducing pain, number of tender joints, duration of morning stiffness, use of non-steroidal anti-inflammatory 
drugs and improving physical performance in RA patients (33).

Alam et al, studied the effects of dietary fats on the inflammatory mediators in the alveolar bone. They found that these types of dietary lipids had a profound influence on the fatty acid composition of bone lipids. The arachidonic acid concentrations were significantly lower in the total phospholipids of the mandibles and maxillae of rats fed on the fish oil diets than in those fed with the control diet. Arachidonic acid is a precursor of prostaglandin E2 and leukotriene $\mathrm{C} 4$, a significant reduction in its concentration may result in reduced levels of these eicosanoids in the alveolar bone (34).

In addition, previous studies showed that omega- 3 fatty acid-derived lipid mediators, known as resolvins and protectins, may play an important role in resolving inflammation since they have potent anti-inflammatory properties. These both mediators also inhibit inflammationinduced bone resorption and directly modulate osteoclast differentiation and prevent bone resorption (35-37).

Several studies have reported that n-3 PUFA eicosapentaenoic acid (EPA) and docosahexaenoic acid (DHA) abundant in fatty fish oils are known to have significant anti-inflammatory properties and positive effects on bone metabolism, possibly via suppressing proinflammatory mediators like prostaglandin E2 (PGE2), interleukins IL-1, IL-6 and tumor necrosis factor TNF- $\alpha$, which are known to promote osteoclastogenesis and increase bone loss $(38,39)$.

\section{CONCLUSION}

Proper nutrition plays a vital role in the well-being of a person. Fish oil rich in omega-3 fatty acids have a proven role in resolving inflammation. Not only the lack of serious side effects and the positive health benefits of fish oil, but also its remarkable therapeutic effect proven from this study in case of rheumatoid arthritis induced rats, it should be considered as an acceptable approach for most arthritic individuals.

\section{CONFLICT OF INTEREST}

The authors declare that they have no conflicts of interest.

\section{REFERENCES}

1. Bevaart L, Vervoordeldonk MJ, Tak PP. Evaluation of Therapeutic Targets in Animal Models of Arthritis. How Does It Relate to Rheumatoid Arthritis? Arthritis Rheum. 2010; 62:2192-205.

2. Grassi W, De Angelis R, Lamanna G, Cervini C. The clinical rheumatoid arthritis. Eur J Radiol. 1998; 27:18-24.

3. Block SR. Guidelines for the management of rheumatoid arthritis. Arthritis Rheum. 2002; 46:328-46.

4. Müller-Ladner U, Pap T, Gay RE, Neidhart M, Gay S. Mechanisms of disease: the molecular and cellular basis of joint destruction in rheumatoid arthritis. Nat Clin Pract Rheumatol. 2005; 1:102-10.

5. Haynes DR, Crotti TN, Loric M, Bain GI, Atkins GJ, Findlay DM. Osteoprotegrin and receptor activator of nuclear factor kappa B ligand (RANKL) regulate osteoclast formation by cells in the human rheumatoid arthritis joint. Rheumatology. 2001:40; 623-30.
6. Corrado A, Neve A, Maruotti N, Cantatore FP. Bone effects of biologic drugs in rheumatoid arthritis. Clin Dev Immunol. 2013; 2013:1-7.

7. Fit N, Chirilă F, Răpuntean S, Nadăş G, Preoteasa L, Cumpănaşu F. Haematological and biochemical investigations in rats with rheumatoid arthritis induced by Freund Complete Adjuvant and treated with bee venom. Veterinary Medicine. 2011; 68; 151-8.

8. Kässer UR, Gleissner C, Dehne F, Michel A, Willershausen-Zönnchen B, Bolten WW. Risk for periodontal disease in patients with longstanding rheumatoid arthritis. Arthritis Rheum. 1997; 40:2248-51.

9. Mercado F, Marshall R. Inter-relationships between rheumatoid arthritis and periodontal disease. Journal of Clinical Periodontology. 2003; 30:761-72.

10. Pischon N, Pischon T. Association among rheumatoid arthritis, oral hygiene, and periodontitis. Journal of Periodontology. 2008; 79:979-86.

11. Maroon JC, Bost JB. Nature's safest, most effective antiinflammatory: fish oil: the natural anti-inflammatory. Library of congress: E-Publishing; 2006:37.

12. Turchini GM, Wing-Keong NG, Tocher DR. Fish oil replacement and alternative lipid sources in aquaculture feeds. Tyalor and Francis group: E-Publishing; 2010:12-13.

13. Leeb BF, Sautner J, Andel I, Rintelen B. Intravenous application of omega-3 fatty acids in patients with active rheumatoid arthritis. Lipids. 2006;41:29-34

14. Simopoulos AP. The importance of the omega-6/omega-3 fatty acid ratio in cardiovascular disease and other chronic diseases. Exp Biol Med. 2008; 233:674-88.

15. Firestein GS, Budd RC, Gabriel SE, Mcinnes IB, O'dell JR. Kelley's textbook of rheumatology. $9^{\text {th }}$ ed. Elsevier Inc.; 2013:1049-52.

16. Kremer JM. N-3 fatty acids supplements in rheumatoid arthritis. Am J Clin Nutr. 2000; 71:349-51.

17. Kesavalu L, Vasudevan B, Raghu B, Browning E, Dawson D, Novak JM. Omega-3 fatty acid effect on alveolar bone loss in rats. J Dent Res. 2006:85:648-52.

18. Sun D, Krishnan A, Zaman K, Lawrence R, Bhattacharya A, Fernandes G. Dietary n-3 fatty acids decrease osteoclastogenesis and loss of bone mass in ovariectomized mice. J Bone Miner Res. 2003; 18:1206-16.

19. Hasturk H, Kantarci A, Ohira T, Arita M, Ebrahimi N, Chiang N. RvE1 protects from local inflammation and osteoclast-mediated bone destruction in periodontitis. FASEB J. 2006; 20:401-3.

20. Banji D, Pinnapureddy J, Otilia JF, Banji A, Kumar R. Evaluation of the concomitant use of methotrexate and curcumin on Freund's complete adjuvant-induced arthritis and hematological indices in rats. Narsi Reddy Indian J Pharmacol. 2011; 43: 546-50.

21. Vardar S1, Buduneli E, Türkoğlu O, Berdeli AH, Baylas H, Başkesen A, et al. Therapeutic versus prophylactic plus therapeutic administration of omega-3 fatty acid on endotoxin-induced periodontitis in rats. 2004; 75:1640-6.

22. Suresh P1, KavithaChN, Babu SM, Reddy VP, Latha AK. Effect of ethanol extract of Trigonella foenumgraecum (Fenugreek) seeds on Freund's adjuvant-induced arthritis in albino rats. 2012; 35:1314-21.

23. Bashkar SN. Orban oral histology and embryology. Torteno: Mosby; 1990:365-473.

24. Dunn CA, Jin Q, Taba M, Renny T. Franceschi, R. BMD gene delivery for alveolar bone engineering at dental implants defects. Molecular therapy. 2005; 11; 295-9. 
25. Kirkpatrick LA, Feeney BC. A simple guide to IBM SPSS statistics for version 20.0. Student ed. Belmont, Calif.: Wadsworth, Cengage Learning; 2013.

26. Fit N, Chirila F, Rapuntean S, Nadas G. Haematological and Biochemical Investigations in Rats with Rheumatoid Arthritis Induced by Freund Complete Adjuvant and Treated with Bee Venom. Veterinary Medicine. 2011; 68:151-8.

27. Aizer J, Reed G, Onofrei A, Harisson MJ. Predictors of bone density testing in patients with rheumatoid arthritis. Rheumatol Int. 2009; 29:897-905.

28. Park JC, Su C, Jung IH, Choi SH. Mechanism of alveolar bone loss in a collagen-induced arthritis model in mice. 2011; 38:122-30.

29. Bernstein CN, Blanchard JF, Leslie W, Wajda A. The incidence of fracture among patients with inflammatory bowel disease: a population-based cohort study. Annals of Internal Medicine. 2000; 133:95-100.

30. Bultink IEM, Lems WF, Kostense PJ, Dijkmans BAC, Voskuyl AE. Prevalence of and risk factors for low bone mineral density and vertebral fractures in patients with systemic lupus erythematosus. Arthritis and Rheumatism. 2005; 52: 2044-50.

31. Sambrook PN. The skeleton in rheumatoid arthritis: common mechanisms for bone erosion and osteoporosis. J Rheumatol. 2000; 27:2541-2.

32. Bahadori B, Uitz E, Thonhofer R. Omega-3-fatty acid infusions as adjuvant therapy in rheumatoid arthritis. J Parenter Enteral Nutr. 2010; 34:151-5.

33. Ruggiero C, Lattanzio F, Lauretani F, Gasperini B, AndresLacueva $\mathrm{C}$, Cherubini A. Omega-3 polyunsaturated fatty acids and immune-mediated diseases: inflammatory bowel disease and rheumatoid arthritis. 2009; 15:4135-48.

34. Alam SQ, Kokkinos PP, Alam BS. Fatty acid composition and arachidonic acid concentrations in alveolar bone of rats fed diets with different lipids. Calcif Tissue Int. 1993; $35-$ 52.

35. Serhan CN, Gotlinger K, Hong S, Arita M. Resolvins, docosatrienes, and neuroprotectins, novel omega-3-derived mediators, and their aspirin-triggered endogenous epimers: an overview of their protective roles in catabasis. Prostaglandins Other Lipid Mediat. 2004; 73:155-72.

36. Herrera BS, Ohira T, Gao L, Omori K, Yang R. An endogenous regulator of inflammation, resolvin $\mathrm{E} 1$, modulates osteoclast differentiation and bone resorption. $\mathrm{Br}$ J Pharmacol. 2008; 155:1214-23.

37. Poulsen RC, Gotlinger $\mathrm{KH}$, Serhan $\mathrm{CN}$, Kruger MC. Identification of inflammatory and proresolving lipid mediators in bone marrow and their lipidomic profiles with ovariectomy and omega-3 intake. Am J Hematol. 2008; 83:437-45.

38. James MJ, Gibson RA, Cleland LG. Dietary polyunsaturated fatty acids and inflammatory mediator production. Am J Clin Nutr. 2000; 71:343-8.

39. Poulsen RC, Moughan PJ, Kruger MC. Longchainpolyunsaturated fatty acids and the regulation of bone metabolism. Exp Biol Med. 2007; 232:1275-88. 